\title{
Fracionamento de carboidratos e de proteína das silagens de diferentes forrageiras
}

\section{Pablo Teixeira Viana ${ }^{1}$, Aureliano José Vieira Pires ${ }^{2}$, Leandro Barbosa de Oliveira ${ }^{3}$, Gleidson Giordano Pinto de Carvalho ${ }^{4}$, Leandro Sampaio Oliveira Ribeiro ${ }^{5}$, Daiane Maria Trindade Chagas $^{6}$, Carlos Souza Nascimento Filho ${ }^{1}$, Aline Oliveira Carvalho ${ }^{1}$}

\author{
1 UESB, Itapetinga, BA. Bolsista de Iniciação Científica do CNPq. \\ ${ }^{2}$ DTRA/UESB, Itapetinga. Pesquisador do CNPq. \\ 3 Programa de Pós-Graduação em Agronomia, UESB, Vitória da Conquista, BA. Bolsista da FAPESB. \\ ${ }^{4}$ DPA/UFBA, Salvador, BA. \\ 5 Programa de Pós-Graduação em Zootecnia, UESB, Itapetinga, BA. Bolsista da FAPESB. \\ ${ }^{6}$ Programa de Pós-Graduação em Zootecnia, UESB, Itapetinga, BA. Bolsista da CAPES.
}

RESUMO - Este experimento foi conduzido com os objetivos de caracterizar e quantificar as frações que compõem os carboidratos e a proteína de diferentes silagens. Foi utilizado delineamento inteiramente casualizado com quatro tratamentos e cinco repetições: silagem de milho (AG 5011), silagem de sorgo-sudão, silagem de sorgo-forrageiro (BR 601) e silagem de girassol (Rumbsol 91). A silagem de girassol apresentou menor valor de carboidratos totais (CT) e da fração B2 (fração potencialmente degradável da fibra). As silagens de milho, sorgo-sudão e sorgo-forrageiro não apresentaram diferença quanto aos teores de carboidratos totais. A fração C (fração indigestível da parede celular) foi encontrada em maior proporção nas silagens de sorgo-sudão e girassol. Não houve diferenças na fração A da proteína (nitrogênio não-proteico) entre as silagens. A silagem de girassol apresentou maior valor de proteína bruta e nitrogênio total. Não foi observada diferença nos resultados entre as silagens de milho e sorgo, e a fração C foi menor para silagem de milho e sorgo forrageiro. As silagens de sorgo-sudão e sorgo-forrageiro apresentam menor valor nutritivo, devido à maior quantidade de parede celular e ao menor conteúdo de energia em comparação às silagens de milho e girassol.

Palavras-chave: avaliação de alimentos, girassol, milho, sorgo

\section{Fractioning of carbohydrates and protein of silages of different forages}

ABSTRACT - This experiment was conducted to characterize and quantify the fractions that make up the carbohydrate and protein in silages. The design was completely randomized with four replications and five treatments: corn silage (AG 5011), sorghumsudangrass silage, forage sorghum silage (BR 601) and sunflower silage (Rumbsol 91). Sunflower silage had the lowest value of total carbohydrates (TC) and B2 fraction (potentially degradable fraction of the fiber). Silages of corn, forage sorghum and sorghumsudangrass showed no difference in cholesterol levels. Fraction C (indigestible cell wall fraction) was higher in silages of sunflower and sorghum-sudangrass. There was no effect on the protein fraction (non-protein nitrogen) between silages. Sunflower silage showed higher crude protein and total nitrogen. No differences were found between the silages of maize and sorghum, and fraction C was smaller for the corn silage and forage sorghum. Silages of corn, forage sorghum and sorghum-sudangrass presented lower nutritional value due to the greater amount of cell wall and less energy, when compared with silages of corn and sunflower.

Key Words: feed evaluation, maize, sorghum, sunflower

\section{Introdução}

O suprimento das necessidades nutricionais de ruminantes depende principalmente do conteúdo de energia e proteína da dieta que podem ser utilizadas pela microbiota ruminal. Segundo Mello \& Nörnberg (2004), a fermentação ruminal depende da concentração total de carboidratos e proteínas na dieta e de suas taxas de degradação. O valor nutricional de uma silagem depende essencialmente da cultivar utilizada, do estádio de maturação no momento do corte e da natureza do processo fermentativo, o que refletirá diretamente no desempenho animal (Vilela, 1985).

$\mathrm{O}$ uso de forrageiras conservadas na forma de silagem é uma prática comum utilizada por produtores. O milho e o sorgo são as forrageiras mais utilizadas para a produção de silagem (Pires et al., 2009), entretanto, outras forrageiras, como o girassol, são alternativas para esta prática, que, além de suprir a deficiência de forragem, também fornece 
alimentos de qualidade satisfatória, devido ao seu alto potencial forrageiro e valor nutritivo, para manter os índices produtivos e reprodutivos do rebanho durante o ano.

O sorgo tem sido uma opção vantajosa em regiões mais secas onde o milho não produz bem (Oliveira et al., 2010). É uma das forrageiras mais empregadas na região semiárida do Brasil, por apresentar produção de matéria seca (MS) mais elevada em comparação ao milho (Molina et al., 2003) e silagem de qualidade, com teores de energia satisfatórios para suprir às exigências nutricionais dos animais. Por outro lado, o girassol é caracterizado por apresentar boa tolerância a períodos secos e ampla adaptabilidade às diferentes condições edafoclimáticas. A composição bromatológica da silagem de girassol difere da observada na silagem de milho ou sorgo, com maiores teores de proteína bruta e extrato etéreo.

O milho é uma das melhores forrageiras para ensilar, pois apresenta boa produção de MS por hectare e elevado valor nutritivo. No momento propício ao corte, possui adequado teor de MS e carboidratos solúveis, o que lhe confere ótimas condições para conservação na forma de silagem (Almeida et al., 2003), produzindo alimento de ótima qualidade e boa aceitação pelos animais.

Objetivou-se com este trabalho determinar o valor nutritivo por meio de frações que compõem os carboidratos e a proteína das silagens de milho, sorgo-sudão, sorgoforrageiro e girassol.

\section{Material e Métodos}

O experimento foi conduzido no Setor de Forragicultura e Pastagens da Universidade Estadual do Sudoeste da Bahia, UESB, no Campus de Itapetinga, Bahia. A precipitação durante os meses de condução do experimento foi de $320 \mathrm{~mm}$. O delineamento experimental utilizado foi inteiramente casualizado com quatro tratamentos e cinco repetições: silagem de milho (AG 5011), silagem de sorgosudão, silagem de sorgo-forrageiro (BR 601) e silagem de girassol (Rumbsol 91). Foram utilizados silos de PVC com 50 cm de altura por 10 cm de diâmetro providos de válvulas de Bunsen.

O número de dias para colheita foi de 69 para o sorgoforrageiro, 75 para o sorgo-sudão e 77 para o milho e o girassol. As forrageiras foram cortadas, desintegradas em picadora estacionária em partículas com tamanho médio de $2 \mathrm{~cm}$ e ensiladas quando atingiram condições ideais para ensilagem. Os silos foram compactados obedecendo a uma densidade de $600 \mathrm{~kg}$ de matéria natural $/ \mathrm{m}^{3}$. Em seguida, foram vedados e pesados permanecendo armazenados por um período de 60 dias.
Após o período de armazenamento, foram abertos e amostras foram coletadas. As amostras foram homogeneizadas e pré-secas em temperatura controlada a $60^{\circ} \mathrm{C}$ por 72 horas e, posteriormente, trituradas em moinho tipo Wiley com peneira de malha de $1 \mathrm{~mm}$ para posteriores análises, quando foram avaliados os teores de matéria seca (MS), proteína bruta (PB), nitrogênio insolúvel em detergente neutro (NIDN), nitrogênio insolúvel em detergente ácido (NIDA), extrato etéreo (EE), fibra em detergente neutro (FDN), fibra em detergente ácido (FDA), lignina, celulose e hemicelulose, segundo procedimentos descritos por Silva \& Queiroz (2002).

Foram estimadas as frações nitrogenadas $\left(A, B_{1}+B_{2}\right.$, $B_{3}$ e C) e de carboidratos $\left(A+B_{1}, B_{2}\right.$ e C). A porcentagem de carboidratos totais (CT) foi obtida pela equação (Sniffen et al., 1992): $\mathrm{CT}=100-(\% \mathrm{~PB}+\% \mathrm{EE}+\%$ cinza $)$; a de carboidratos fibrosos (CF), a partir da FDN corrigida para seu conteúdo de cinzas e proteínas (FDNcp); os carboidratos não-fibrosos (CNF), que correspondem às frações $\mathrm{A}+\mathrm{B} 1$, pela diferença entre os carboidratos totais e a FDNcp (Hall, 2003); e a fração C, pela FDN indigestível após 144 horas de incubação in situ (Cabral et al., 2004). A fração B2, que corresponde à fração disponível da fibra, foi obtida pela diferença entre a FDNcp e a fração C.

A fração B3 foi estimada pela diferença entre NIDN e NIDA e a proteína verdadeira (frações B1 + B2), pela diferença entre o nitrogênio total e o nitrogênio insolúvel em ácido tricloracético (TCA), e a frações C, correspondente ao NIDA. O teor de nitrogênio não-proteico (fração A) foi calculado como a diferença entre o percentual do nitrogênio total na amostra e o valor de nitrogênio proteico contido no resíduo após o tratamento com o agente precipitante TCA. Procedeu-se, então, à estimativa do teor de nitrogênio no resíduo pelo método Macro Kjedal. Os nutrientes digestíveis totais (NDT) foram estimados conforme descrito por Cappelle et al. (2001).

Os dados foram analisados por meio de análise de variância e teste Tukey a 5\% de probabilidade utilizando o programa SAEG versão 9.1 (Ribeiro Júnior, 2001).

\section{Resultados e Discussão}

Os maiores teores de carboidratos totais foram observados $(\mathrm{P}<0,05)$ nas silagens de milho, sorgo-sudão e sorgo-forrageiro e o menor na silagem de girassol. Os menores teores de proteína bruta e extrato etéreo do material ensilado (6,0 e 4,1\%; 6,8 e 3,8\%; 5,5 e 3,8\%) e das respectivas silagens de milho e de sorgo-sudão e forrageiro (8,6 e 4,0\%; 9,1 e 4,9\%; 9,1 e 3,5\%), respectivamente, contribuíram para os maiores valores de carboidratos totais observados nas 
silagens produzidas (Tabela 2). Os maiores teores de PB e EE observados na silagem de girassol foram decorrentes do maior teor observado no material ensilado: 8,0 e 10,2, respectivamente (Tabela 1). Os valores de carboidratos totais obtidos neste estudo corroboram aqueles relatados por Van Soest (1994), constituindo 50 a 80\% da matéria seca das plantas forrageiras.

Os teores de NDT foram maiores $(\mathrm{P}<0,05)$ na silagem de girassol, seguida da silagem de milho, cujos teores foram superiores aos das silagens de sorgo-sudão e sorgo-forrageiro (Tabela 2). O maior valor encontrado na silagem de girassol pode ser devido ao fato de o girassol ter apresentado maior concentração de extrato etéreo (Tabela 1). O conteúdo de NDT é importante, uma vez que a energia e proteína são frequentemente os fatores mais limitantes para ruminantes (Oliveira et al., 2010). Os resultados de NDT encontrados para silagem de milho e de sorgo foram inferiores ao recomendado por Keplin (1992), de 64 a 70\% como valores ideais para silagens de boa qualidade.
Para as frações A + B1 (\% CT), foram encontrados maiores $(\mathrm{P}<0,05)$ valores nas silagens de girassol e milho, respectivamente, seguidas das silagens de sorgo forrageiro e sorgo-sudão. Alimentos com elevada fração A + B1 são considerados boas fontes energéticas para aumento no conteúdo dos microrganismos ruminais (Carvalho et al., 2007) e o sincronismo entre a taxa de digestão das proteínas e dos carboidratos, podendo ter importante efeito sobre os produtos finais da fermentação e sobre a produção animal (Nocek \& Russell, 1988). Nesse contexto, o amido presente nos grãos de girassol contribuiu para o aumento da fração $\mathrm{A}+\mathrm{B} 1$ das silagens. O maior teor de CNF, representado pelas frações A + B1, teoricamente aumentaria o conteúdo de NDT, uma vez que estes carboidratos apresentam quase completa disponibilidade nutricional em ruminantes (Mertens, 1996; Cabral et al., 2003).

De acordo com Sniffen et al. (1992), a fração A é composta de açúcares e a fração B1, de amido, pectina e glucanas. A pectina, apesar de estar localizada na parede

Tabela 1 - Composição químico-bromatológica do milho, sorgo-sudão, sorgo-forrageiro e do girassol no momento da ensilagem

\begin{tabular}{|c|c|c|c|c|}
\hline Nutriente & Milho & Sorgo-sudão & Sorgo-forrageiro & Girassol \\
\hline Matéria seca (\%) & 31,2 & 29,5 & 28,2 & 19,0 \\
\hline Proteína bruta (\% MS) & 6,0 & 6,8 & 5,5 & 8,0 \\
\hline Extrato etéreo (\% MS) & 4,1 & 3,8 & 3,8 & 10,3 \\
\hline NIDN/NT & 19,7 & 21,0 & 21,0 & 19,4 \\
\hline NIDA/NT & 6,8 & 8,9 & 8,0 & 10,3 \\
\hline Fibra em detergente neutro (\% MS) & 60,0 & 61,8 & 56,9 & 44,5 \\
\hline Fibra em detergente ácido (\% MS) & 39,2 & 46,2 & 41,1 & 40,9 \\
\hline Celulose (\% MS) & 34,8 & 38,4 & 35,8 & 33,4 \\
\hline Hemicelulose (\% MS) & 20,7 & 15,6 & 15,7 & 3,5 \\
\hline Lignina (\% MS) & 4,8 & 7,6 & 5,1 & 8,5 \\
\hline Carboidratos totais (\% MS) & 83,3 & 81,2 & 82,0 & 67,8 \\
\hline
\end{tabular}

NIDN/NT - nitrogênio insolúvel em detergente neutro em \% do nitrogênio total.

NIDA/NT - nitrogênio insolúvel em detergente ácido em \% do nitrogênio total.

Tabela 2 - Composição químico-bromatológica das silagens de milho, sorgo-sudão, sorgo-forrageiro e girassol

\begin{tabular}{|c|c|c|c|c|c|}
\hline Nutriente & $\begin{array}{l}\text { Silagem } \\
\text { de milho }\end{array}$ & $\begin{array}{c}\text { Silagem de } \\
\text { sorgo-sudão }\end{array}$ & $\begin{array}{c}\text { Silagem de } \\
\text { sorgo-forrageiro }\end{array}$ & $\begin{array}{c}\text { Silagem } \\
\text { de girassol }\end{array}$ & $\mathrm{CV}, \%$ \\
\hline Matéria seca (\%) & $27,5 \mathrm{a}$ & $22,8 b$ & $21,7 b$ & $20,8 b$ & 6,5 \\
\hline Proteína bruta (\% MS) & $8,6 b$ & $9,1 b$ & $9,1 b$ & $12,1 \mathrm{a}$ & 11,3 \\
\hline FDNcp (\% MS) & $54,7 \mathrm{~b}$ & $62,3 a$ & $58,6 a b$ & $37,1 \mathrm{c}$ & 4,2 \\
\hline FDA (\% MS) & $33,1 b$ & $42,9 a$ & $40,8 \mathrm{a}$ & $33,2 b$ & 4,6 \\
\hline NIDN/NT & $18,8 b$ & $28,0 \mathrm{a}$ & $27,0 \mathrm{a}$ & $21,0 \mathrm{ab}$ & 18,0 \\
\hline Hemicelulose (\% MS) & $25,6 a$ & $25,1 \mathrm{a}$ & $25,2 \mathrm{a}$ & $8,6 b$ & 5,4 \\
\hline Celulose (\% MS) & $29,0 b$ & $35,0 \mathrm{a}$ & $34,6 a$ & $26,5 c$ & 3,4 \\
\hline Lignina (\% MS) & $3,5 \mathrm{c}$ & $6,8 \mathrm{a}$ & $4,9 b$ & $7,0 \mathrm{a}$ & 8,3 \\
\hline Extrato etéreo (\% MS) & $4,0 \mathrm{~b}$ & $4,9 b$ & $3,5 b$ & $13,6 a$ & 24,7 \\
\hline NDT (\% MS) & $54,5 b$ & $47,3 c$ & $49,0 \mathrm{c}$ & $67,4 a$ & 2,5 \\
\hline
\end{tabular}

FDN - fibra em detergente neutro; FDA - fibra em detergente ácido; FDNcp - fibra em detergente neutro corrigida para cinza e proteína; NIDN/NT - nitrogênio insolúve em detergente neutro em \% do nitrogênio total; NIDA/NT - nitrogênio insolúvel em detergente ácido em \% do nitrogênio total; NDT - nutrientes digestíveis totais estimado conforme Cappelle et al. (2001).

Médias seguidas da mesma letra na linha não diferem estatisticamente a 5\% pelo teste Tukey.

CV - coeficiente de variação (\%). 
celular, pode ser incluída na fração que compreende o conteúdo celular, pois preenche os requisitos de polissacarídeos não-amiláceos e é rapidamente digerida no rúmen (Van Soest et al., 1991).

A silagem de girassol apresentou as menores quantidades da fração B2 e maiores da fração C, uma vez que essa cultura apresentou menor teor de FDN (Tabela 1), promovido pela ausência ou pequena concentração de hemicelulose. As silagens de milho, sorgo-sudão e sorgoforrageiro apresentaram para a fração B2 valores de 42,0; 40,7 e 44,8\%, respectivamente. O valor mais elevado dessa fração nestas silagens deve-se, principalmente, à maior contribuição de colmo nas plantas de sorgo e espigas no milho. As diferenças entre culturas são justificadas, em grande parte, pelas diferenças nas características estruturais das plantas (Mello \& Nörnberg, 2004). Nos resultados obtidos, foram observado valores menores $(\mathrm{P}<0,05)$ nas frações de FDN e celulose das culturas de milho e girassol (Tabela 2), justificando seu potencial nutricional em relação às demais culturas, conforme relataram Oliveira et al. (2010) e Rodrigues et al. (2001). A variação existente na composição de cada planta reflete diretamente na qualidade e no valor nutritivo da silagem. Malafaia et al. (1998) destacaram que o valor da fração B2 dos alimentos está relacionado ao teor de FDN, pois, em estudos realizados com diversos alimentos, ficou evidenciado que as gramíneas foram os volumosos com os maiores valores da fração B2, em decorrência dos maiores teores de FDN.

Houve diferença $(\mathrm{P}<0,05)$ na fração $\mathrm{C}$ entre as silagens (Tabela 3), representada pela FDNi. Valores superiores foram encontrados nas silagens de sorgo-sudão (39,3\% carboidratos totais) e girassol (35,5\% carboidratos totais), seguida das silagens de milho e sorgo-forrageiro. Como a FDNi inclui a porção da parede celular vegetal não digerida ao longo do trato gastrintestinal (Sniffen et al., 1992), é possível que o acréscimo desta fração nas duas silagens tenha sido ocasionado pelo elevado teor de lignina encontrado (Tabela 2). Contudo, a fração B2, principal componente das silagens de forrageiras tropicais, por apresentar lenta taxa de degradação, juntamente com a fração C (indigestível) normalmente afeta o consumo animal pelo fator enchimento, reduzindo o desempenho dos animais (Mertens, 1987). Portanto, são necessários maiores cuidados com a cultura a ser utilizada e a época à ensilagem.

Não houve diferença $(\mathrm{P}>0,05)$ no conteúdo de nitrogênio total (NT) entre as silagens de milho, sorgosudão e sorgo-forrageiro, cujos valores foram semelhantes: 1,4; 1,5 e 1,5\% da MS, correspondendo a 8,6; 9,1 e 9,1\% de $\mathrm{PB}$, respectivamente. Os resultados encontrados foram semelhantes aos obtidos por Cabral et al. (2003) em silagem de híbridos de sorgo. Os valores de PB encontrados neste estudo são superiores aos relatados por Oliveira et al. (2010), de 6,1; 6,3 e 6,1\% para as silagens de milho, sorgosudão e sorgo-forrageiro. A silagem de girassol destacou-se por apresentar maior valor (12,1\% de PB), ocasionado pela grande quantidade de folhas e pelo maior teor de PB da planta na ocasião da colheita (Tabela 1).

Todas as culturas apresentaram valores de PB superiores ao mínimo de 7\% recomendado por Van Soest (1994) como adequado para funcionamento da microbiota do rúmen. Contudo, foram próximos das faixas normalmente registradas por outros autores, 8,0; 8,2 e 8,8\% para milho, sorgo e girassol, respectivamente (Velho et al., 2007; Cabral et al., 2003; Tomich et al., 2004), em pesquisas com silagens de diferentes gramíneas (Carvalho et al., 2008).

Não houve efeito $(\mathrm{P}>0,05)$ das forrageiras sobre a fração A, composta por nitrogênio não-proteico (NNP), das silagens, pois os resultados foram estatisticamente similares (Tabela 4). Com a fermentação da massa ensilada, boa parte da proteína é convertida em nitrogênio não-proteico, em decorrência da proteólise (Pires et al., 2009). Os resultados encontrados diferem dos descritos por Mello \& Nörnberg (2004), que, avaliando silagens de diferentes forrageiras, encontraram menores níveis da fração A para diferentes híbridos de milho (DKB-215 e DKB-344) e sorgo (Ambar e AG 2005) e maiores para o girassol (Rumbosol e M-734). Isso explica que, além dos resultados encontrados entre cultivares, há diferenças entre híbridos de mesma cultura.

Tabela 3 - Teores percentuais médios de carboidratos totais (CT), carboidratos não-fibrosos (A+B1), componentes disponíveis correspondentes à fração potencialmente degradável (B2) e fração indigestível da parede celular (C) de silagens de milho, sorgo-sudão, sorgo-forrageiro e girassol

\begin{tabular}{|c|c|c|c|c|c|}
\hline Item & $\begin{array}{l}\text { Silagem } \\
\text { de milho }\end{array}$ & $\begin{array}{l}\text { Silagem de } \\
\text { sorgo-sudão }\end{array}$ & $\begin{array}{c}\text { Silagem de } \\
\text { sorgo-forrageiro }\end{array}$ & $\begin{array}{c}\text { Silagem } \\
\text { de girassol }\end{array}$ & $\mathrm{CV}, \%$ \\
\hline Carboidratos totais (\%MS) & $80,7 \mathrm{a}$ & $77,8 \mathrm{a}$ & $78,7 \mathrm{a}$ & $59,5 b$ & 2,3 \\
\hline Fração A + B1 (\%CT) & $32,2 b$ & $19,9 d$ & $25,4 c$ & $37,8 \mathrm{a}$ & 10,2 \\
\hline Fração B2 (\%CT) & $42,0 \mathrm{a}$ & $40,7 a$ & $44,8 \mathrm{a}$ & $26,8 b$ & 12,0 \\
\hline Fração C (\%CT) & $25,8 c$ & 39,3a & 29,8 bc & $35,5 a b$ & 9,9 \\
\hline
\end{tabular}

Médias seguidas da mesma letra na linha não diferem estatisticamente a 5\% pelo teste Tukey.

CV - coeficiente de variação (\%). 
Tabela 4 - Teores percentuais médios de nitrogênio total (NT), fração constituída de nitrogênio não-proteico (A), fração de rápida e de intermediária degradação $\left(\mathrm{B}_{1}+\mathrm{B}_{2}\right)$, fração de lenta degradação $\left(\mathrm{B}_{3}\right)$ e fração não-digestível $(\mathrm{C})$ das silagens de milho, sorgosudão, sorgo-forrageiro e girassol

\begin{tabular}{lcccc}
\hline Item & $\begin{array}{c}\text { Silagem } \\
\text { de milho }\end{array}$ & $\begin{array}{c}\text { Silagem de } \\
\text { sorgo-sudão }\end{array}$ & $\begin{array}{c}\text { Silagem de } \\
\text { sorgo-forrageiro }\end{array}$ & $\begin{array}{c}\text { Silagem } \\
\text { de girassol }\end{array}$ \\
\hline Nitrogênio total (\%MS) & $1,4 \mathrm{~b}$ & $1,4 \mathrm{~b}$ & $1,4 \mathrm{~b}$ & $1,9 \mathrm{a}$ \\
Fração A (\%NT) & $12,3 \mathrm{a}$ & $12,3 \mathrm{a}$ & $13,7 \mathrm{a}$ & $12,2 \mathrm{a}$ \\
Fração B1 + B2 (\%NT) & $68,9 \mathrm{a}$ & $58,9 \mathrm{~b}$ & $59,5 \mathrm{~b}$ & 13,3 \\
Fração B3 (\%NT) & $7,7 \mathrm{a}$ & $7,7 \mathrm{a}$ & $5,1 \mathrm{~b}$ & $85,9 \mathrm{ab}$ \\
Fração C (\%NT) & $14,1 \mathrm{c}$ & $20,6 \mathrm{a}$ & $13,7 \mathrm{~b}$ & 13,7 \\
\hline
\end{tabular}

Médias seguidas da mesma letra na linha não diferem estatisticamente a 5\% pelo teste Tukey.

CV - coeficiente de variação (\%).

As frações B1 e B2 neste estudo foram consideradas fração única (B1 + B2) e se referem (Pires et al., 2009) às proteínas solúveis e insolúveis verdadeiras. Os maiores valores foram observados nas silagens de milho e girassol (Tabela 4), não havendo diferenças $(\mathrm{P}>0,05)$ para as silagens de sorgo-sudão e sorgo-forrageiro. Por outras metodologias de fracionamento das proteínas, como as utilizadas por Mello \& Nörnberg (2004), não é possível determinar a fração B1, pois esta fração é altamente degradável. Van Soest (1994) também não encontrou contribuições da fração B1 da proteína em silagens de milho e sorgo. No CNCPS (2002) toda a fração B1 é considerada como degradada no rúmen (Sniffen et al., 1992).

Segundo Valadares Filho (2000), em relação à avaliação proteica dos alimentos para ruminantes, nem todo fracionamento proteico feito pelo CNCPS (2002) deveria ser adotado no Brasil. Entretanto, dependendo da finalidade da pesquisa, o fracionamento conforme descrito por este torna-se necessário, principalmente quando se pretende calcular o escape ruminal de proteína oriundo de cada uma dessas frações. Contudo, os resultados encontrados neste estudo destacam as silagens de milho e girassol com maior porção de proteína verdadeira, fração (B1 + B2), 68,9 e 65,9 em (\%NT), respectivamente, disponível para a microbiota ruminal em relação às silagens de sorgo.

A fração B3 (\%NT) foi maior nas silagens de milho e sorgo-sudão $(\mathrm{P}<0,05)$, seguida das silagens de sorgo forrageiro e girassol (Tabela 4). Essa fração proteica (B3), apesar de digerível, possui taxa de degradação ruminal de 0,02 a 1,0\% h-1 (Sniffen et al., 1992; Pires et al., 2009). A fração B3 é representada pela fração proteica ligada à parede celular que apresenta lenta taxa de degradação (Cabral et al., 2004; Carvalho et al., 2008).

Já a fração considerada indigestível (C), mensurada pela quantificação do teor de NIDA nas silagens, teve efeito significativo $(\mathrm{P}<0,05)$, com maior valor para a silagem de sorgo-sudão, seguida das silagens de sorgo-forrageiro e girassol, sendo que a silagem de milho apresentou menor fração indigestível (Tabela 4). O maior valor da fração C encontrado na silagem de sorgo-sudão pode ser explicado pelo maior teor de NIDA (Tabela 2) presente na silagem. Essa fração proteica corresponde à proteína associada à lignina, complexos taninoproteína e produtos oriundos da reação de Maillard, altamente resistentes às enzimas microbianas e indigestíveis ao longo do trato gastrintestinal (Licitra et al., 1996).

Esses dados comprovam a diversidade de resultados entre culturas de diferentes forrageiras, mostrando a importância de fracionar para melhor entendimento dos mesmos para adequado balanceamento de dietas em função das exigências de animais em diferentes categorias.

\section{Conclusões}

As silagens de sorgo-sudão e sorgo-forrageiro apresentam menor valor nutritivo, devido à maior quantidade de parede celular e menor energia. A silagem de girassol apresenta maior valor energético, em função da presença do extrato etéreo, em comparação às demais.

\section{Referências}

ALMEIDA, J.C.C.; REIS, R.A.; RODRIGUES, L.R.A. et al. Cultivars silage evaluation of the corn (Zea mays L.) and sorghum (Sorghum vulgare, Pers.) sowing in different density. Revista Universidade Rural: Série Ciências da Vida, v.23, n.1, p.47-57, 2003.

CABRAL, L.S.; VALADARES FILHO, S.C.; DETMANN, E. et al. Composição químico-bromatológica, produção de gás, digestibilidade in vitro da matéria seca e NDT estimado da silagem de sorgo com diferentes proporções de panículas. Revista Brasileira de Zootecnia, v.32, n.5, p.1250-1258, 2003.

CABRAL, L.S.; VALADARES FILHO, S.C.; DETMANN, E. et al. Taxas de digestão das frações protéicas e de carboidratos para as silagens de milho e de capim-elefante, o feno de capim-Tifton85 e o farelo de soja. Revista Brasileira de Zootecnia, v.33, n.6, p.1573-1580, 2004.

CAPPELLE, E.R.; VALADARES FILHO, S.C.; SILVA, J.F.C. et al. Estimativas do valor energético a partir de características químicas e bromatológicas dos alimentos. Revista Brasileira de Zootecnia, v.30, n.6, p.1837-1856, 2001. 
CARVALHO, G.G.P.; GARCIA, R.; PIRES, A.J.V. et al. Fracionamento de carboidratos de silagem de capim-elefante emurchecido ou com farelo de cacau. Revista Brasileira de Zootecnia, v.36, n.4, p.1000-1005, 2007.

CARVALHO, G.G.P.; GARCIA, R.; PIRES, A.J.V. et al. Fracionamento de proteínas de silagem de capim-elefante emurchecido ou com farelo de cacau. Ciência Animal Brasileira, v.9, n.3, p.648-656, 2008.

CNCPS. Cornell net carbohydrate and protein system. Ithaca: Cornell University, 2002. Software, version 5.0.18.

HALL, M.B. Challenges with nonfiber carbohydrate methods. Journal of Animal Science, v.81, n.12, p.3226-3232, 2003.

KEPLIN, L.A.S. Recomendação sorgo e milho (silagem) safra 1992/93. Encarte técnico da Revista Batavo. CCLPL, Castro, PR. Ano I, n.8, p.16-19, 1992.

LICITRA, G.; HERNANDEZ, T.M.; Van SOEST, P.J. Standardization of procedures for nitrogen fractionation of ruminant feeds. Animal Feed Science and Technology, v.57, n.4, p.347-358, 1996.

MALAFAIA, P.A.M.; VALADARES FILHO, S.C.; VIEIRA, R.A.M. et al. Determinação das frações que constituem os carboidratos totais e da cinética ruminal da fibra em detergente neutro de alguns alimentos para ruminantes. Revista Brasileira de Zootecnia, v.27, n.4, p.790-796, 1998.

MELLO, R.; NÖRNBERG, J.L. Fracionamento dos carboidratos e proteínas de silagens de milho, sorgo e girassol. Ciência Rural, v.34, n.5, p.1537-1542, 2004.

MERTENS, D.R. Predicting intake and digestibility using mathematical models of ruminal function. Journal of Animal Science, v.64, n.5, p.1548-1558, 1987.

MERTENS, D.R. Using fiber and carbohydrate analyses to formulate dairy rations. In: INFORMATIONAL CONFERENCE WITH DAIRY AND FORAGES INDUSTRIES, 1996, Wisconsin. Proceedings... Wisconsin: 1996.

MOLINA, L.R.; RODRIGUEZ, N.M.; SOUZA, B.M. et al. Parâmetros de degradabilidade potencial da matéria seca da proteína bruta das silagens de seis genótipos de sorgo (Sorghum bicolor (L.) Moench), com e sem tanino no grão, avaliados pela técnica in situ. Revista Brasileira de Zootecnia, v.32, n.1, p.222-228, 2003.

NOCEK, J.E.; RUSSELL, J.B. Protein and energy as an integrated system: relationship of ruminal protein and carbohydrate availability to microbial synthesis and milk production. Journal of Dairy Science, v.71, n.8, p.2070-2107, 1988.

OLIVEIRA, L.B.; PIRES, A.J.V.; CARVALHO, G.G.P. et al. Perdas e valor nutritivo de silagens de milho, sorgo Sudão, sorgo forrageiro e girassol. Revista Brasileira de Zootecnia, v.39, n.1, p.61-67, 2010.

PIRES, A.J.V.; CARVALHO, G.G.P.; GARCIA, R. et al. Fracionamento de carboidratos e proteínas de silagens de capim-elefante com casca de café, farelo de cacau ou farelo de mandioca. Revista Brasileira de Zootecnia, v.38, n.3, p.422-427, 2009.

RIBEIRO JÚNIOR, J.I. Análise estatística no SAEG. Viçosa, MG: UFV, 2001. 301p.

RODRIGUES, P.H.M.; ALMEIDA, T.F.; MELOTTI, L. et al. Efeitos da adição de inoculantes microbianos sobre a composição bromatológica e sobre a fermentação da silagem de girassol produzida em silos experimentais. Revista Brasileira de Zootecnia, v.30, n.6S, p.2169-2175, 2001.

SILVA, D.J.; QUEIROZ, A.C. Análise de alimentos: métodos químicos e biológicos. Viçosa, MG: Editora UFV, 2002. 235p.

SNIFFEN, C.J.; O’CONNOR, J.D.; VAN SOEST, P.J. et al. A net carbohydrate and protein system for evaluating cattle diets: II - Carbohydrate and protein availability. Journal of Animal Science, v.70, n.12, p.3562-3577, 1992.

TOMICH, T.B.; GONÇALVES, L.C.; TOMICH, R.G.P. et al. Características químicas e digestibilidade in vitro de silagens de girassol. Revista Brasileira de Zootecnia, v.33, n.6, p.1672-1682, 2004.

VALADARES FILHO, S.C. Nutrição, avaliação de alimentos e tabelas de composição de alimentos para bovinos. In: REUNIÃO ANUAL DA SOCIEDADE BRASILEIRA DE ZOOTECNIA, 37. 2000, Viçosa, MG. Anais... Viçosa, MG: Sociedade Brasileira de Zootecnia, 2000. p.267.

VAN SOEST, P.J. Nutritional ecology of the ruminant. 2.ed Ithaca, New York : Cornell University, 1994. 476p.

VAN SOEST, P.J.; ROBERTS, J.B.; LEWIS, B.A. Methods for dietary fibre, neutral detergent fibre and non-starch polysaccharides in relation to animal nutrition. Journal of Dairy Science, v.74, n.10, p.3583-3597, 1991.

VELHO, J.P.; MÜHLBACH, P.R.F.; NÖRNBERG, J.L. et al. Composição bromatológica de silagens de milho produzidas com diferentes densidades de compactação. Revista Brasileira de Zootecnia, v.36, n.5, p.1532-1538, 2007.

VILELA, D. Sistemas de conservação de forragem. 1. silagem. Coronel Pacheco: EMBRAPA - CNPGL, 1985. 42p. (Boletim de Pesquisa, 11). 